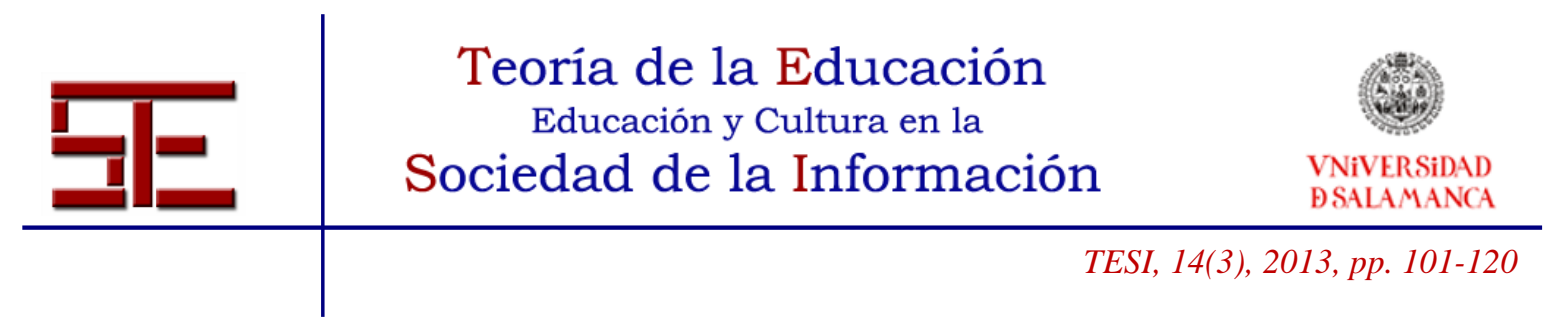

\title{
JUGANDO A SER DIOSES: PUNTOS CRÍTICOS DE LAS TECNOLOGÍAS EN EDUCACIÓN
}

Resumen: La convivencia de la educación con los medios tecnológicos arrastra una complicada relación que afecta, sin duda, de manera asimétrica más a la primera que a los segundos. La presencia de estos en los escenarios educativos tiene una desigual intensidad atendiendo a factores tan variados como la voluntad de sus protagonistas, tanto docentes como discentes, a la presión social, especialmente de los mismos discentes y sus familias, y por supuesto a las iniciativas gubernamentales, en algunos momentos más invasivas de lo debido. Este panorama no cambia con la universalización de los medios sociales digitales sino que más bien agudiza algunas brechas que ya eran evidentes con medios más rudimentarios. El artículo aporta tres niveles de análisis, a modo de puntos críticos, para pensar las tecnologías en la educación, desde la constatación de que hemos decidido jugar a ser dioses, en el sentido que nos hemos creído con la capacidad de crear desde cero y reinventarnos cada día.

Palabras clave: medios sociales, redes sociales, web 2.0, epistemología, metodologías colaborativas

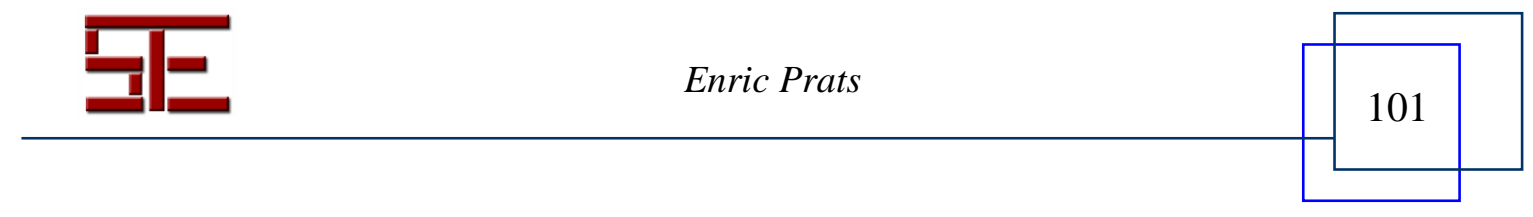




\title{
PLAYING TO BE GODS: CRITICAL ISSUES IN EDUCATION TECHNOLOGIES
}

\begin{abstract}
The coexistence of education and technology drags a complicated relationship that affects asymmetrically more to the former than the latter. Its presence in schools has an uneven intensity due to factors as varied as the will of its protagonists, both teachers and learners, the social pressure, especially the learners themselves and their families, and the government initiatives, at times more invasive than they should. This landscape does not change with the universalization of digital social media but rather sharpens some gaps that were evident with means more rudimentary. The paper provides three levels of analysis, by way of on one each critical points, in order to think about technology in education, from the realization that we have decided to play to be Gods, in the sense that we have believed in the ability to create from scratch and reinvent each day.
\end{abstract}

Key words: social media, networking, web 2.0, epistemologies, collaborative methodologies

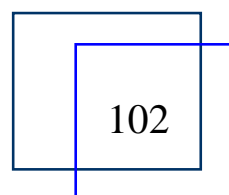




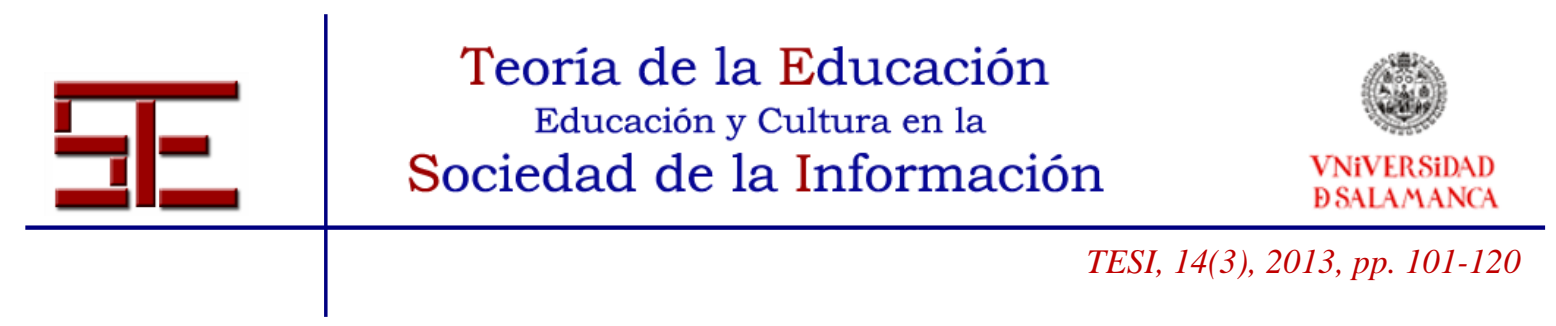

\section{JUGANDO A SER DIOSES: PUNTOS CRÍTICOS DE LAS TECNOLOGÍAS EN EDUCACIÓN}

Fecha de recepción: 14/06/2013; fecha de aceptación: 25/07/2013; fecha de publicación: 30/11/2013

Enric Prats

enricprats@ub.edu

Universitat de Barcelona

\section{1.-OBJETO DE DEBATE Y ESTADO DE LA CUESTIÓN}

"Nada es más absurdo ni intolerable que la omnipresencia del hambre en el siglo XXI, edad de oro de la ciencia y la tecnología". Con este alegato a la reflexión sobre la necesidad de tomar medidas contra la plaga del hambre, el anterior presidente de Brasil, Lula da Silva, hacía su primera comparecencia ante Naciones Unidas, en 2003. Y remataba con la siguiente aseveración: "Mientras más celebramos a Dios generando riquezas, más perjudicamos nuestros ideales al no compartirlas aunque sea en forma mínima.” (Da Silva 2003). Con toda seguridad no fue el primer dirigente político, y no será el último, que con toda la buena voluntad hace un llamamiento hacia un uso más "humano" de las posibilidades creativas e innovadoras para transformar las condiciones de vida de los más desfavorecidos, ahora que tenemos una alta capacidad de intervenir y controlar precisamente esas condiciones.

La apelación a la posición central que la tecnología, junto con la ciencia, ocupa en las sociedades desarrolladas alerta, al mismo tiempo, sobre la necesidad de reflexionar acerca de los límites sociales, pedagógicos y epistemológicos que ese dominio supone en un campo, el educativo, muy sensible a los cambios, y a un dominio académico, la pedagogía, que siempre se ha mostrado ambivalente ante los mismos. Lo antedicho no es óbice para recordar que las tecnologías no dejan de ser inventos humanos y que, en condición de tal origen, reflejan las contradicciones y limitaciones de sus protagonistas. En realidad, las tecnologías no dan sentido a nada, ya que ese sentido, cuando se da, expresará siempre la mano de quien esté detrás.

El mundo de la tecnología sufre unos cambios sumamente acelerados, en cantidad y en calidad, que desbancan cualquier previsión y suponen un reto de alto nivel para la educación. Desde este punto de vista, su integración en las aulas y las escuelas padece un recorrido errático y en verdad complicado por cuanto ese proceso refleja, como decíamos, las mismas contradicciones que cualquier actividad humana. No se trata tan solo de acometer el debate entre tecnofílicos y tecnofóbicos o de resolver las incontables, y quizás inevitables, interferencias del sector productivo para formar individuos con las debidas competencias digitales. El núcleo del debate del papel de las tecnologías en la educación radica en su condición mutable, casi líquida, que obliga a replantearse lo hecho con una frecuencia inusitada. Si dichas observaciones, acerca del

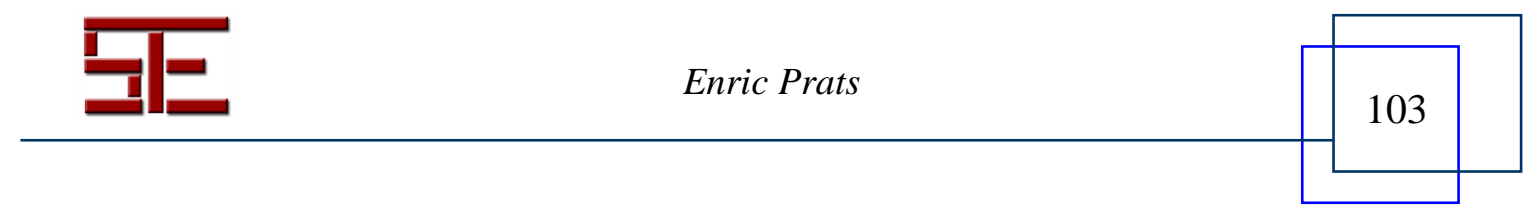




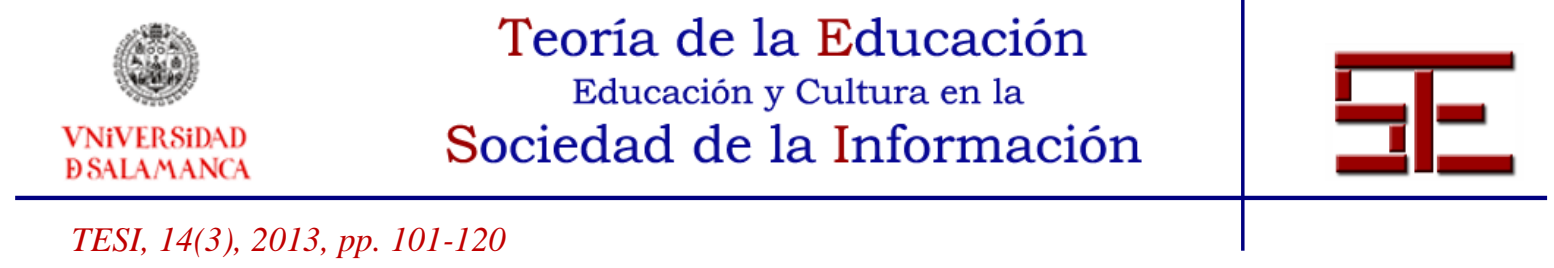

encontronazo entre partidarios y contrarios a las tecnologías, y acerca de las competencias necesarias para moverse en este mundo, se resuelven mediante el sentido común y el sentido de la realidad, este tercer punto advierte sobre la capacidad del sistema educativo de reponerse a sí mismo y, más que nada, de la idoneidad del profesorado para liderar ese cambio.

En este sentido, los principios y las finalidades que quizás servían para encauzar proyectos educativos en un marco dominado por los medios audiovisuales, particularmente la televisión y los medios masivos de comunicación, quedan obsoletos y casi inservibles cuando nos enfrentamos a un marco definido por los medios sociales digitales. Incluso en este mismo ambiente digital, las soluciones pedagógicas adoptadas en el contexto de la web 1.0 pueden quedar envejecidas con la implantación de la web 2.0 .

En este artículo se profundiza en tres niveles de análisis que, a modo de puntos críticos, nos permiten alertar de la precaria situación de las tecnologías en la educación formal, al mismo tiempo que se proponen caminos de debate para un desarrollo más afianzado de dicha implementación. Cabe recordar, ante todo, que estamos cerrando el cerco a las tecnologías entendidas como artefactos humanos que aportan versatilidad e inmediatez, entre otras muchas virtudes, pero también incertidumbre y ansiedad, por citar sus inconvenientes menos dramáticos. Antes de decidirnos a crear de cero, algo que nos podemos permitir desde ahora en educación con determinadas tecnologías, quizás sea momento de acometer un examen escrupuloso sobre los límites sociológicos, pedagógicos y epistemológicos de su uso en la educación. En suma, la digitalización en clave 2.0 somete a la pedagogía, y quizás especialmente a la teoría de la educación, a revisar sus postulados y a plantear nuevos interrogantes, algunos de los cuales, sin ánimo de exhaustividad, se recogen en las páginas siguientes.

\section{2.-PRIMER NIVEL: EL EMPUJE DE LO SOCIAL EN EDUCACIÓN}

No deja de ser un ejercicio intelectual atractivo el pensar acerca de lo que la pedagogía, en su sentido de disciplina teórico-reflexiva, hubiera dicho con motivo de la aparición o invención de la escritura. Es lugar común el prestigio social que en todos los tiempos ha gozado el letrado ante el iletrado, el que domina el código ante el analfabeto. La paleografía ha informado de esos niveles y jerarquías que introdujo o, para ser más exactos, bendijo la escritura en las sociedades arcaicas, a modo de instrumento que permitía marcar la distancia entre lo efímero, el habla, y lo duradero, la escritura (Castillo y Sáez 1994, 136).

En un ejercicio de ucronía pedagógica, podríamos imaginar lo que habría podido suceder en el supuesto de que la alfabetización digital hubiera antecedido a la alfabetización analógica, algo técnicamente poco probable. Como es sabido, las

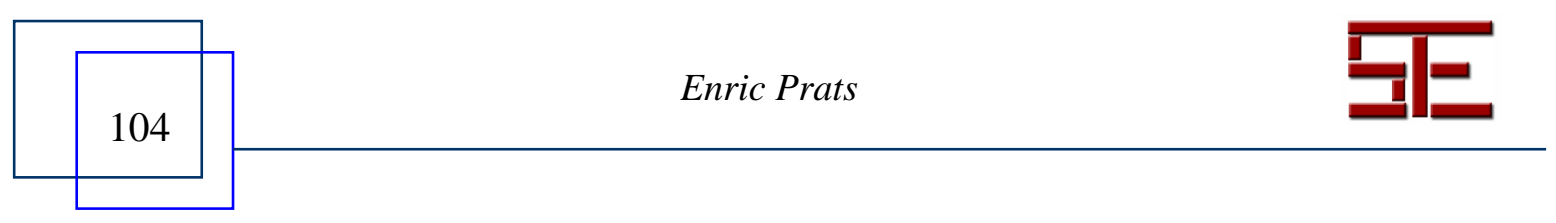




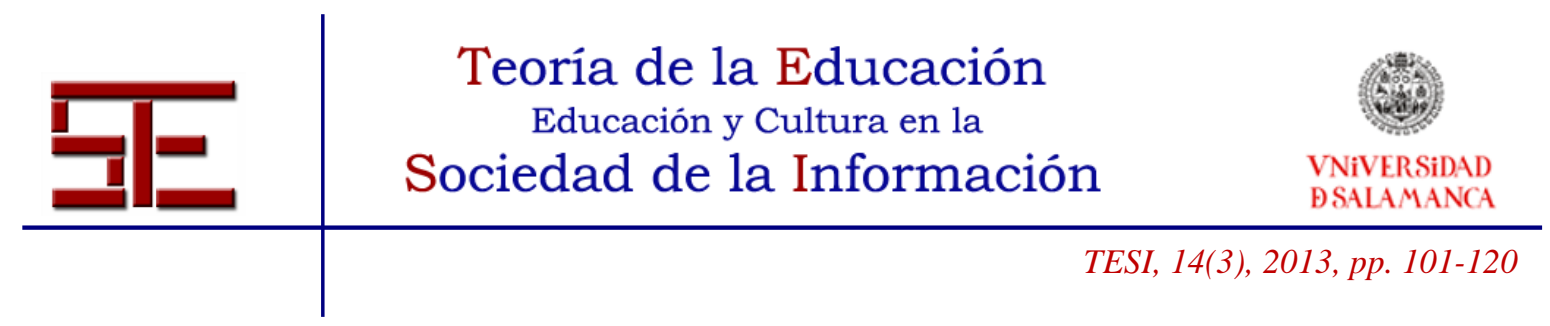

medidas discretas, propias de la tecnología digital, con base 2, se oponen a las medidas continuas de los dispositivos analógicos, que admiten infinidad de puntos intermedios. En un escenario de estas características, ese predominio de las medidas discretas podría haber generado la implantación de un modelo social, sin duda jerárquico, pero algo distinto del que conocemos. En educación, pudiera haber desembocado en unos diseños instructivos ciertamente distintos, prestando más atención a lo discreto que a lo continuo, a la generalización antes que al detalle, a lo universal más que a lo particular. Si nos fijamos, exactamente estos presupuestos se ajustan a las proclamas líquidas de flexibilización y adaptación constante a los cambios: cuanto más global sea nuestra perspectiva más capacidad de actuar.

Ese es el salto contrario que estamos experimentando con el paso de lo analógico a lo digital. Así, la pedagogía ha acuñado el término alfabetizaciones para referir un conjunto de dimensiones que trascienden el mero hecho decodificador, de marcado acento mecánico, y atender a la necesidad de estudiar el fenómeno desde su complejidad (Viñao 1992, 386). Y en el mismo sentido, el Consejo de la Unión Europea, en una reciente declaración, asumía ya la necesidad de atender las "alfabetizaciones múltiples", reconociendo que el "aumento de la digitalización exige unos niveles de alfabetización múltiple aún más altos [...]. Además, las redes sociales han aumentado la importancia y la visibilidad de las competencias de escritura" (DOC 2012, 1).

Podemos asegurar, por lo tanto, que la implantación masiva de dispositivos ultrasofisticados, que trascienden la mera función comunicativa, sientan las bases para un cambio importante también en clave social. La era postPC, donde se superan las limitaciones técnicas que habían presidido los primeros momentos de aparición de nuevas tecnologías, donde sólo los iniciados aprovechaban al máximo las posibilidades de los medios, dibuja un escenario que altera incluso la jerarquización social del conocimiento, como veremos más adelante. Es una evidencia que entre los más jóvenes es donde se han dado las condiciones para una implantación masiva de dispositivos móviles sofisticados.

\subsection{Ante el uso lúdico y social}

Puestas así las cosas, lo que demuestran los datos es el uso lúdico y social casi exclusivo de los dispositivos electrónicos, especialmente entre los jóvenes pero también en adultos, lo cual pone contra las cuerdas concepciones pedagógicas casi ancestrales. La presencia doméstica de los ordenadores y de ordenadores conectados a Internet es abrumadora.

En pocos años hemos alcanzado unos niveles de "conexión" semejantes a los vecinos europeos, como recogen los datos de Eurostat. Esa realidad se ve aumentada con la presencia de menores en el hogar (Eurostat 2012). Según la base de datos europea, los

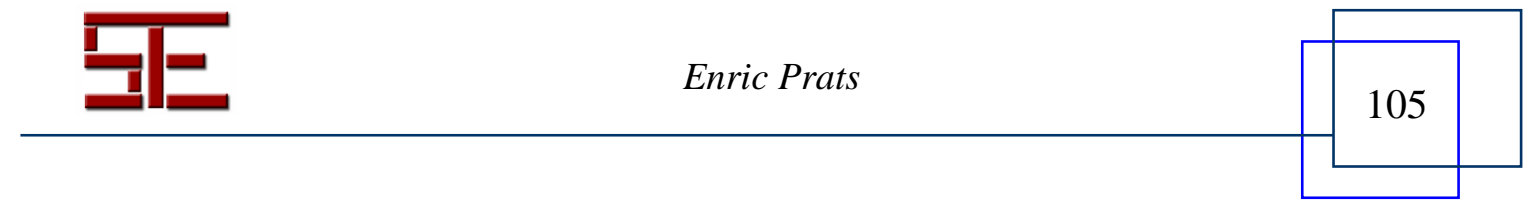




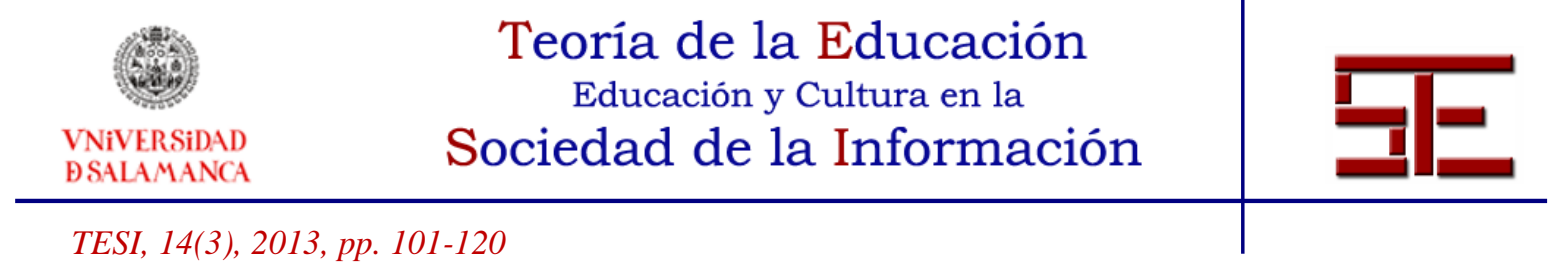

países nórdicos muestran una penetración casi absoluta tanto en ordenadores como en conexión a la Red, con valores que rozan el cien por cien, aunque Finlandia se desmarca de sus vecinos cuando no hay presencia de menores en el hogar. España presenta unos datos interesantes: con menores, el 79\% de los hogares tienen ordenadores conectados; en cambio, ese dato baja al 57\%, más de 20 puntos, cuando no hay menores en el hogar. El empuje que supone quizás la exigencia de ordenador y conexión doméstica por razones educativas, para completar tareas escolares, repasar o ampliar conocimientos y buscar información para trabajos, entre otros usos formativos, no se corresponde con el uso real, recogido por las encuestas, acerca del predominio lúdico (individual pero también en grupo mediante la Red) y social (para chatear, tuitear, cotillear en el Facebook de los amigos, etc.).

En primer lugar, las clásicas pedagogías defensoras del juego, como activo revelador de la inmensa capacidad creativa de los humanos, verían materializados sus postulados al ver de qué manera los artefactos digitales han copado la atención de niños y jóvenes, a través de los cuales se renueva el ideal de aprender jugando. Sin embargo, la reacción más enconada es el rechazo a esta dimensión educativa del juego digital especialmente entre docentes y familias, lo cual vendría a reabrir de nuevo la brecha entre pedagogías. Además de esta polémica, estos dispositivos destapan una paradoja según la cual mientras, por un lado, nos avezamos a encontrar recursos que capten la atracción de los alumnos, por otro lado se rechaza el indudable valor estimulante de los artefactos digitales, que casi llegan a anular por completo a cualquier otro estímulo.

En segundo término, vistas desde afuera, con ojos de adulto escéptico, a veces ignorante, las pantallas cierran posibilidades sociales que serían debidamente atendidas si se dejaran de lado las máquinas y se volviera a las relaciones cara a cara, se jugara en el parque o se quedara para salir con los amigos o amigas. La socialización siempre ha sido considerada un motor de la maduración y el crecimiento personales, un principio que ha inundado todos los espacios educativos, quizás más en los informales y no formales que en los escolares, no siempre demasiado complacientes con esta dimensión social de la educación. Las tecnologías digitales han reabierto, con más crudeza si cabe, este abismo que separa a tecnofóbicos y tecnofílicos cuando se trata de reconocer las virtudes sociales de las máquinas. Por un lado, se apela al peligro aislacionista que suponen las pantallas, que promueven la soledad, el encierro en casa e incluso el ostracismo, como relatan dramáticamente algunos sucesos en la prensa de manera esporádica. Por otro lado, se recuerda que el juego en línea, competitivo o en equipo, es el que gana más adeptos en la Red, incrementando los espacios de socialización y obligando a activar mecanismos de relación con los demás.

Parecería que podríamos aplicar a las tecnologías lo mismo que decíamos en esta misma revista acerca de la modernidad y la postmodernidad en relación a la persona: "si la modernidad descubre al yo, para luego casi anularlo en una masa informe, la

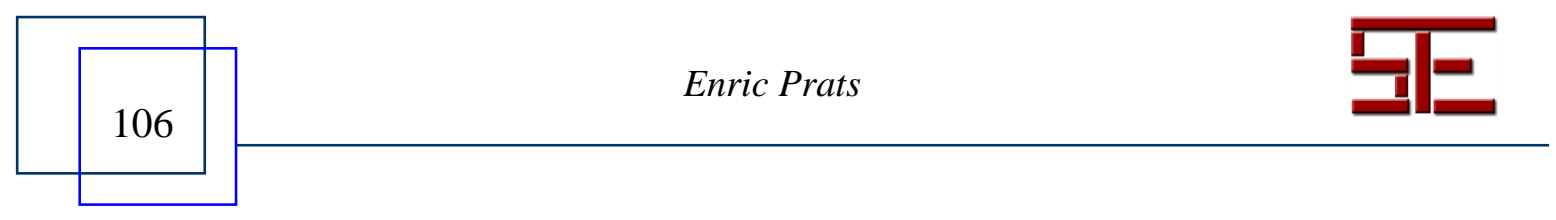




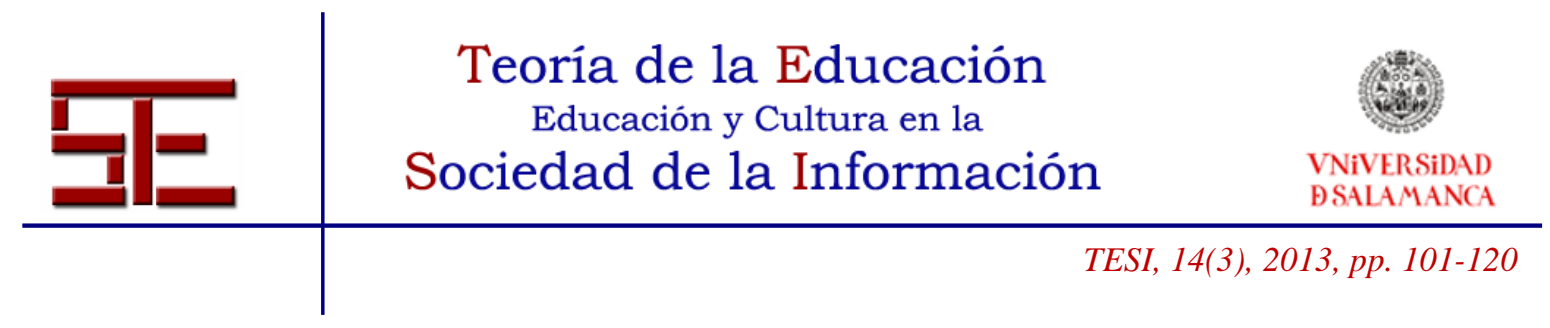

postmodernidad intentará recuperarlo desde el hallazgo de la alteridad, de la heteronomía" (Laudo y Prats 2013, 250). En relación con las tecnologías ha sucedido algo parecido, en el sentido de que las tecnologías del yo, siguiendo la expresión foucaultiana, han sido suplantadas por tecnologías de lo impersonal, y estas a su vez han sido eliminadas a favor de tecnologías intersubjetivas, como expresan los medios sociales.

Sin ninguna duda, las redes digitales replantean la relación que deba existir entre docente y alumnos, de la misma manera que está interfiriendo en las que existen en el seno de las familias, entre progenitores e hijos, pero al mismo tiempo llega a modificar aspectos centrales de la implicación de las familias con la escuela, con una vinculación quizás más estrecha con los tutores (gracias o por culpa del correo electrónico y recientemente de las redes sociales digitales), e incluso entre los mismos docentes.

En definitiva, tanto la vertiente lúdica como la social despiertan los recelos de docentes y familias, seguramente cargados de motivos, pero la pedagogía debería dar una respuesta firme acerca de hasta qué punto se debe aprovechar ese uso lúdico y social tan abrumador para transformarlo en un uso educativo.

\subsection{Desigualdades educativas y niveles de integración}

La presencia notable de ordenadores conectados en casa y la casi implantación generalizada en las escuelas hace pensar en una utilización educativa amplia. Desgraciadamente, los datos no avalan esta suposición. Como recoge Pedró "el uso predominante de la tecnología en los centros escolares gravita en torno a la búsqueda de información en Internet, cuyo porcentaje es casi el doble que la siguiente actividad más extendida: la comunicación con otros alumnos y el trabajo en equipo" (Pedró 2011, 20). Seguramente, este uso dominante admite tres explicaciones: en la versión más sencilla, los usuarios están repitiendo patrones simples de navegación 1.0 preaprendidos, unos patrones que el docente aprovecha para "ahorrarse" parte de la información que debería proporcionar, fomentando el acceso a la búsqueda de datos o hechos en portales planos; otra versión admitiría que los encargos docentes resultan poco creativos o acordes con las herramientas 2.0, desaprovechando o ignorando sus potencialidades; en una tercera explicación, algo más sofisticada, podríamos alertar acerca de la invisibilidad de multitud de iniciativas que pasan desapercibidas a los mecanismos de evaluación al uso, que son incapaces de recoger la realidad que se está produciendo en la Red.

Con el desarrollo de aplicaciones 2.0, lo más probable es que la brecha digital se pueda incrementar también en el ámbito escolar. A estas alturas, contamos con escuelas 2.0, que han hecho de las tecnologías un eje central de su acción educativa, con ordenadores ultraportátiles o tabletas para el uso individual de cada alumno, aulas digitalizadas, trabajos en red con otras escuelas, elaborando productos digitales de primera línea, etc.

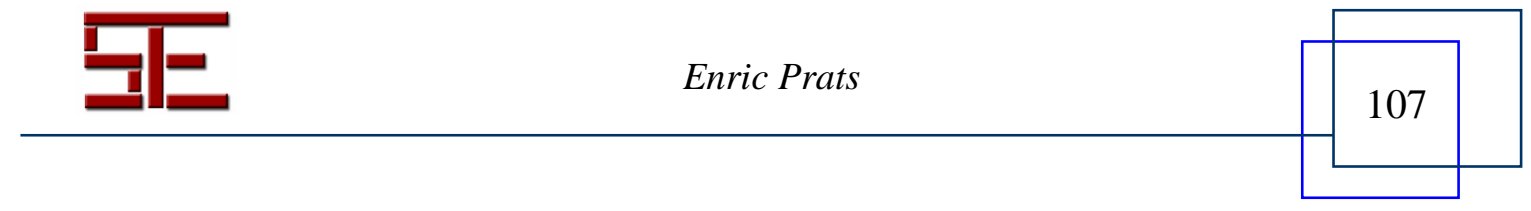




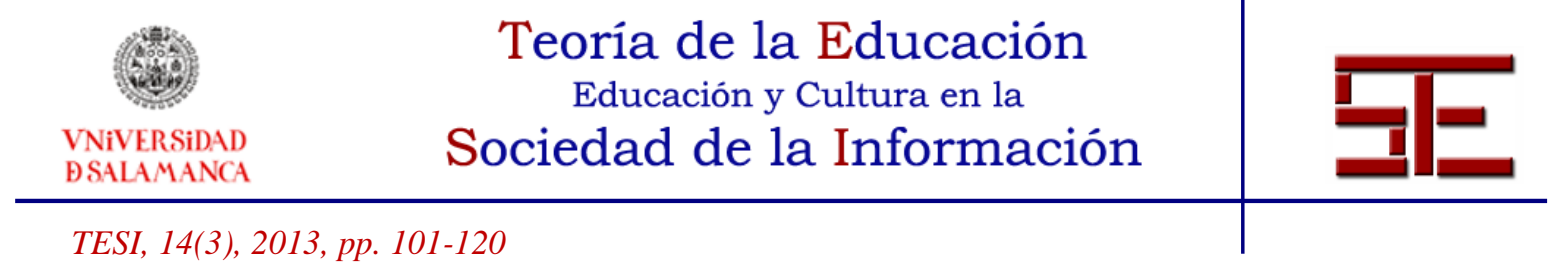

Junto a estas escuelas más avanzadas, podemos encontrar escuelas que podríamos denominar 1.0, que hacen un uso interesante pero todavía escaso o aislado de las tecnologías, normalmente mediante un aula de informática, destinada a trabajar alguna parte de una asignatura o como espacio de uso individual o colectivo similar a la biblioteca escolar. Pero en ese mismo mapa coexisten escuelas 0.0, con una ausencia absoluta de ordenadores y sin ningún tipo de estimulo para usarlos tampoco en casa. Incluso, podríamos tener escuelas que podríamos catalogar en negativo, como -1.0, con una posición contraria a las tecnologías, donde metodologías didácticas aburridas y caducas llegan a desincentivar la posibilidad de que los alumnos utilicen las tecnologías en casa para ampliar conocimientos de los contenidos trabajados en clase, lo que incrementa la separación entre la escuela y el mundo de la vida. En otro plano, un cierto número de escuelas apuestan decididamente por invisibilizar las tecnologías sin menguar su función como herramientas necesarias para el crecimiento personal, pero en un marco distinto del escolar.

En este contexto, que dibuja un panorama desigual en la integración tecnológica en la escuela de manera general, también se puede mezclar el hecho de que dentro de algunas escuelas el interés por las tecnologías haya sido protagonizado por un docente suficientemente interesado, que genera aún más diferencias internas entre profesorado y aulas. Nos podemos encontrar, así, con aulas más avanzadas que otras en una misma escuela puesto que el desnivel mostrado por el profesorado lo avala. Se trata de centros educativos sin ninguna voluntad de acometer un trabajo serio y riguroso con las tecnologías, quizás con claustros enfermos o balcanizados, donde la creatividad y el empuje de docentes aislados ponen en marcha esas iniciativas, interesantes pero siempre aisladas y con un impacto limitado. Esas situaciones provocan comparaciones por parte de los alumnos, entre el docente tecnofóbico y el tecnofílico, lo cual desemboca sin duda en desconcierto cuando no en quejas hacia una u otra manera de hacer.

Por supuesto, en el contexto familiar la situación se reproduce y se generan, quizás con más profundidad, esas desigualdades por una presencia masiva y un uso intensivo de las tecnologías, con más o menos criterio en cuanto a seguridad y adicción por parte de los menores, en comparación con los hogares donde por razones culturales o simplemente económicas su presencia es inexistente o escasa.

Lo que demuestran estas situaciones es la contrariedad que provoca en las generaciones adultas la ignorancia sobre las tecnologías, causante de muchos de los prejuicios en boga. En clave escolar, nos debería hacer reflexionar cómo el profesorado, encuadrado en la discutible etiqueta de "inmigrante digital", vive la experiencia de ser superado por sus alumnos, encajados en la de "nativos digitales", especialmente en el dominio de las tecnologías" (Prensky 2001). En ese dominio, además de la habilidad manual y cognitiva para manejarse con los artefactos de última generación con absoluta rapidez, lo que sorprende a algunos adultos es la natural soltura con la que los jóvenes integran

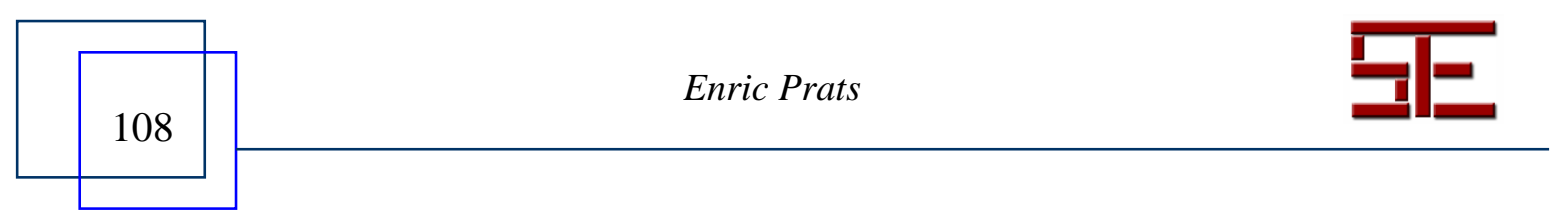




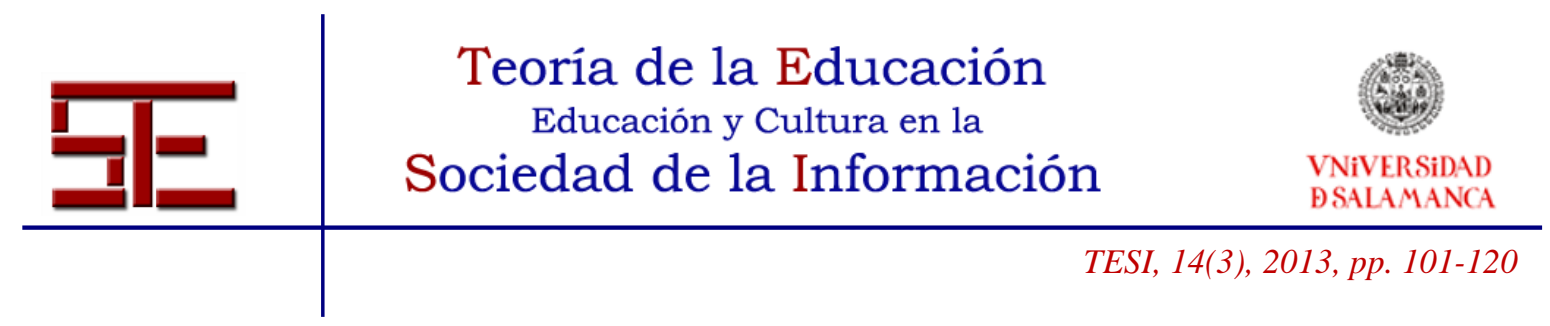

la tecnología en sus vidas, sin los escrúpulos de los adultos. Quizás en esto habrá que aceptar la etiqueta de nativos digitales, derivada de esa naturalidad con la que viven entre tecnologías, porque la dificultad de docentes y familias es precisamente vivir cuando la realidad supera la ficción, cuando la generación joven supera a la que le ha precedido (Bennet, Maton y Kervin 2008).

Y es que la consecuencia de todo ello es la alteración del concepto de autoridad, como veremos más adelante. Tanto en el contexto familiar como en el escolar, la capacidad de los jóvenes por "sorprender" a los adultos puede no tener fin si se incrementa el diferencial de uso y dominio de las tecnologías por parte de los primeros. La educación transmisora, que centraba el foco en el traspaso de conocimientos de una generación a la siguiente, queda en entredicho, primero por parte de los mismos jóvenes pero inmediatamente por los adultos. Lejos de sentenciar su desaparición, una adecuada penetración de las tecnologías en la escuela debería subrayar la importancia del legado quizás no tanto en clave de paquete de contenidos como de conjunto de criterios para valorar precisamente su validez y vigencia.

\section{3.-SEGUNDO NIVEL: LA PEDAGOGÍA EN EL CENTRO}

Tenemos la certeza de que las tecnologías están cambiando nuestras mentes. Al menos esa es la tesis más o menos convincente que algunos intelectuales manejan en sus debates públicos. En un texto de 2010, el escritor sobre temas de tecnología Nicholas Carr alertaba de la transformación que Internet está operando en el cerebro humano, bastante zarandeado por la televisión y sometido ahora a un bombardeo incesante de estímulos en paralelo, lo que lo está convirtiendo en un órgano pasivo incapaz de "almacenar" más información que la que se le pueda proporcionar, según este autor. El problema, para él, es la multitarea, algo que el ordenador, y más todavía el ordenador conectado, eleva a la máxima expresión. Esa virtud tecnológica es contemplada como un riesgo para mentes poco preparadas, ya que "gracias una vez más a la plasticidad de nuestras vías neuronales, cuanto más usemos la Web, más entrenamos nuestro cerebro para distraerse, para procesar la información muy rápidamente y de manera muy eficiente, pero sin atención sostenida. Esto ayuda a explicar por qué a muchos de nosotros nos resulta difícil concentrarnos incluso cuando estamos lejos de nuestros ordenadores" (Carr 2010, 235).

Carr ofrece un alegato en favor "del libro impreso, único dispositivo que asegura la lectura atenta $\mathrm{y}$, por ende, garantiza el pensamiento profundo, frente a los artefactos electrónicos, expresión de lo que el autor denomina lectura y mentes superficiales" (Santos Rego et al 2012, 137). Como recuerda Livingston, la integración escolar de ordenadores en el siglo XXI se lleva a cabo con los mismos presupuestos con los que entró el libro en el XIX, en las manos exclusivas del maestro (Livingston 2011, 10).

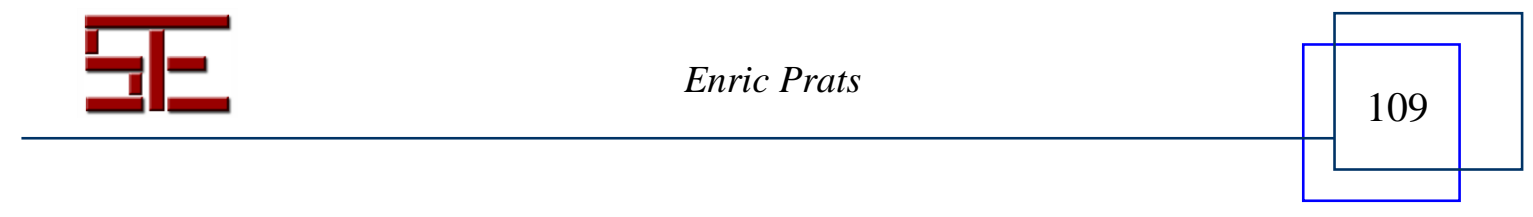




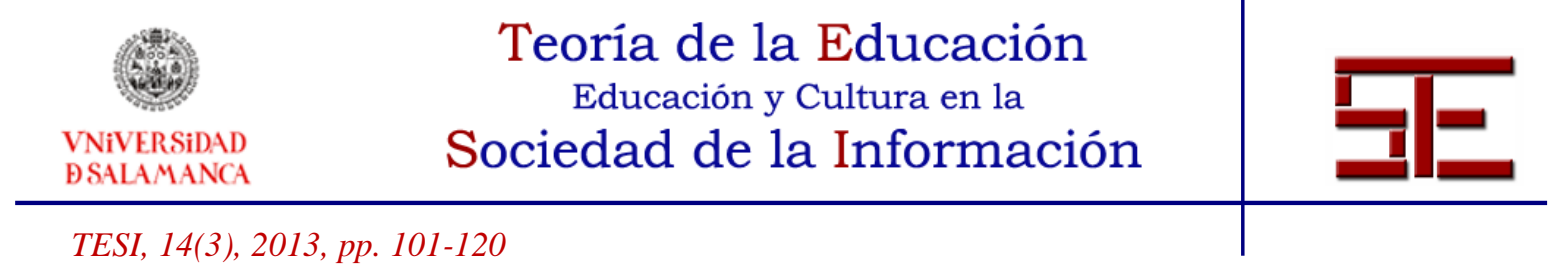

El principal argumento se centra en la gestión multitarea que permite la tecnología digital, ante la gestión secuencial o lineal, que no admite posibilidad alguna de distracción. De hecho, el zapeo, que puestos a ser precisos no sería un invento de la Red, es una de las características de la multimedialidad que, si bien es innegable que supone un reto para la concentración y de lo que se conoce como "lectura interior", no es menos verdad que la inmediatez de acceso a distintas fuentes enriquece nuestra capacidad para encontrar información más precisa y aumentar las posibilidades de generar nuevo conocimiento: el mismo libro de Carr, que denuncia esta liquidez en el proceso de lectura, nos tienta con sus notas a pie de página con numerosas referencias a blogs y webs para que verifiquemos lo que acaba de afirmar o profundicemos en alguna idea expresada en su texto.

Lo cual, curiosamente, no es óbice para afirmar, en versión apocalíptica y conspirativa, que "las distracciones llevan mucho tiempo proliferando por doquier, pero nunca existió un medio como la Red, programado para dispersar nuestra atención de modo tan exhaustivo como insistente" (Carr 2010, 140; la cursiva es nuestra para alertar del extremo que usa el autor). No se puede negar que las tecnologías digitales puedan estar modificando las estructuras mentales (si esta expresión es válida) desarrollados por el ser humano en los últimos milenios, pero parece dudoso que en la escala geológica eso pueda ser equiparable, de momento, a la aparición del lenguaje, como sostiene Carr. En realidad, la memoria humana había quedado liberada por la escritura y por el libro, su dispositivo mágico, que prometió un acceso universal al conocimiento a partir de Guttenberg.

Más allá de cualquier elucubración, sería este un capítulo importante y sumamente sugerente para indagar acerca de la necesidad de repensar la función de los medios tecnológicos como intermediarios que sirven a finalidades educativas, como lo ha sido el libro a lo largo de siglos, y en qué medida estos medios terminan alterando las mismas finalidades, que a su vez requerirán quizás de nuevos medios. Precisamente, lo que permite la web 2.0 es pasar de la receptividad a la productividad, y del trabajo en solitario al cooperativo, donde el usuario hibrida dos procesos, como consumidor y al mismo tiempo como productor de contenidos en línea y en un marco de colaboración. Ello, permite entrar en dos aspectos críticos sobre los cuales la pedagogía deberá profundizar algo más: las competencias digitales y las metodologías colaborativas.

\subsection{Acerca de las competencias digitales}

Podríamos aventurar que en pedagogía existe una inclinación a curricularizar todo lo que nos llevamos entre manos, a convertir en motivo de desarrollo e implementación curricular cualquier necesidad social que despierta la inquietud de políticos y familias, contagia a los responsables y administradores de la educación y termina por convencer

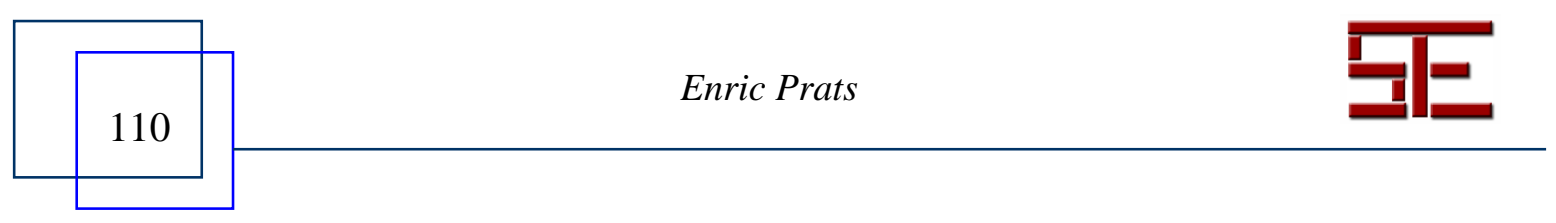




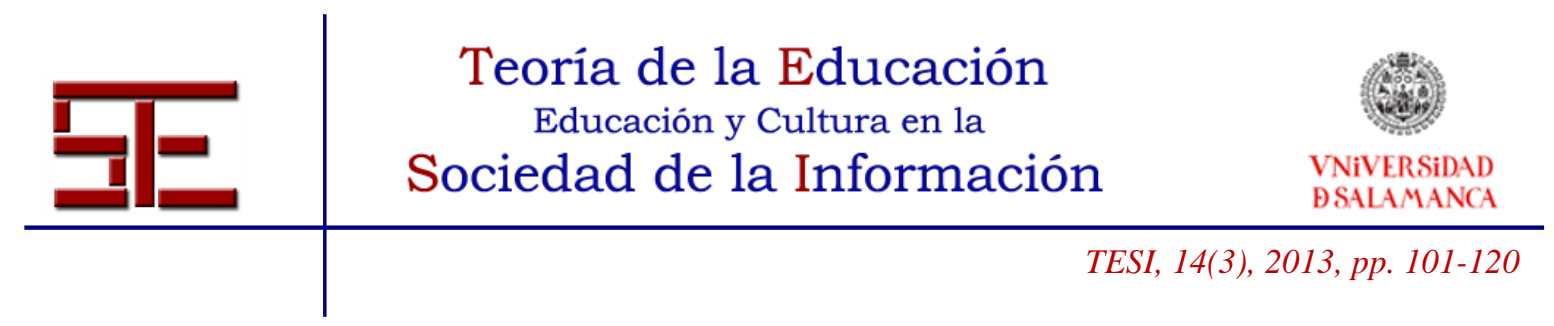

y convertir a docentes. Esta observación es oportuna acerca de las competencias digitales, elevada a competencia básica por la Unión Europea, establecida por la Ley orgánica de educación (LOE), de 2006, y aplaudida por pedagogos y tecnólogos. Seguramente debe ser así.

Lo que se puede plantear es el grado de realismo relacionado con la intención de la escuela de querer asumir en exclusiva esa competencia, algo que suele suceder también con el resto de competencias básicas. Como se ha visto, la elevada penetración de ordenadores en el sector doméstico implica que determinadas habilidades se van adquiriendo, más que nunca, en el ámbito no formal, sin ningún mecanismo de control heterónomo. Eso mismo ocurre con la puesta en práctica de ciertas actitudes y, por extensión, con la conformación del mapa de valores que todo sujeto elabora en su proceso de crecimiento y maduración. A diferencia del aprendizaje formal que se pueda llevar a cabo en un entorno escolarizado, en este caso no se siguen patrones diseñados con una intencionalidad educativa sino que simplemente se siguen pautas informales que desdeñan cualquier hipotético itinerario preestablecido. En otras palabras, el volumen de aprendizajes informales es tan elevado que ningún currículum escolar podría competir para encajarlos en un recorrido formal de diez años de educación básica. Aunque parezca mentira, la escuela no está sola.

Esta preocupación significa que, lejos de abandonar esa tarea, lo que se le exige a la escuela es la necesidad de identificar con claridad el reto y marcar el terreno donde pretende trabajar, con el convencimiento de que está inmersa en un ambiente social y comunitario pero también de que, al menos en este tema, quizás no pueda ser el centro neurálgico o motor de la acción formativa. A tenor de lo dicho, se plantea la pregunta acerca del futuro que esto le depara a la escuela. Si bien, la tecnología pone en tela de juicio su papel y también el del mismo profesorado, no se trata de augurar su final, sino de repensar sus funciones, entre las cuales figura, como la más sofisticada y quizás la más reclamada socialmente, la de evaluar formalmente los aprendizajes alcanzados.

En realidad, lo que hoy se le pide a la escuela con más vehemencia es la tarea de validar y acreditar los conocimientos que van logrando los alumnos. Las leyes que se avecinan en España, adoptando errónea y parcialmente las recomendaciones de organismos internacionales, establecerán estándares territoriales y recogerán el grado de asimilación de esos niveles. Repasando las propuestas legislativas, se detecta que esa competencia digital, más o menos dibujada por las instancias europeas, no aparece en absoluto entre las materias que se evaluarán al final de la educación básica. Y es que el problema radica en cómo se piensa la evaluación: por supuesto, lo que sea la competencia digital no admite una evaluación a la vieja usanza, con preguntas cerradas y respuestas anticipadas porque lo que ponen en evidencia los nuevos dispositivos es precisamente su apertura y discrecionalidad, que impide cerrar cualquier mecanismo de evaluación sumativa relativa a "conocimientos" encuadrados en materias o asignaturas.

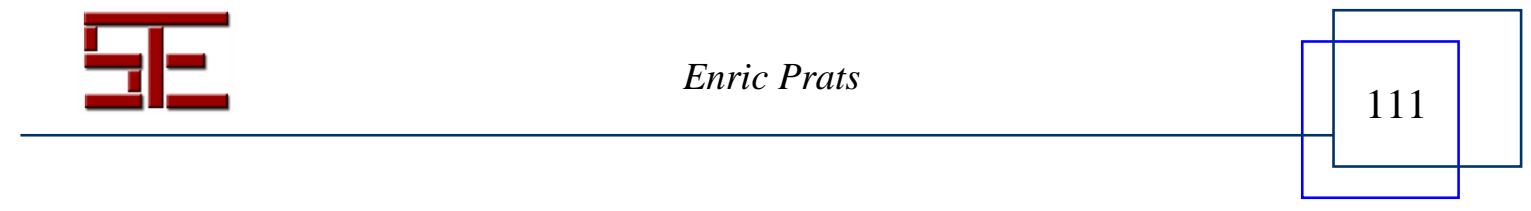




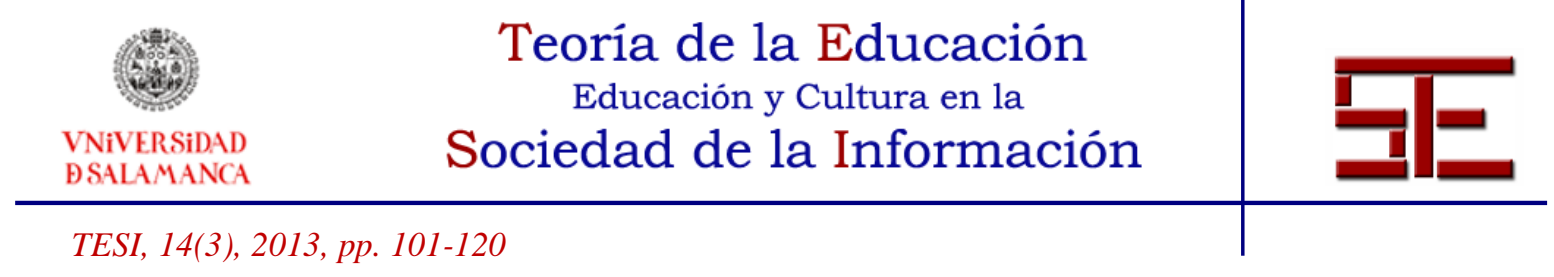

Todo ello exige repensar el mismo concepto de competencia, por no decir el de evaluación. Por ejemplo, el último estudio Pisa (OCDE 2009) recogía la evaluación de las competencias digitales, centradas en el concepto de "lectura digital", y arrojaba unos resultados pobres en términos generales. Teniendo en cuenta que se evalúa a jóvenes de 15 años, el núcleo duro de los "nativos digitales" (Prensky 2001), se esperaban resultados más elevados; en cambio, solo un tercio de la muestra expresaba niveles de lectura digital de nivel elevado o muy elevado, y otro tercio demostraba un nivel bajo o muy bajo. Lo que está ocurriendo es un desfase entre lo que son capaces de hacer los jóvenes y lo que evalúa y analiza el informe Pisa, basado en un concepto de lectura digital quizás algo obsoleto, lo que podría explicar en parte esos pobres resultados. Así, "los textos digitales son concebidos en Pisa como un subconjunto de los textos escritos [como] sinónimo de hipertextos, es decir, un texto o textos que incluyen herramientas de navegación que permiten que el lector se desplace de una página o sitio en Internet a otro" (Pedró 2011, 42). La conclusión del estudio no sorprende: "los resultados de los alumnos en las pruebas de comprensión de lectura digital se ajustan a sus resultados en las pruebas de comprensión lectora (de textos lineales presentados en soporte impreso) en PISA 2009" (Pedró 2011, 43).

A nuestro juicio, esta competencia digital limitada rinde tributo a una interpretación poco cercana a la realidad de lo que podríamos denominar la "vida digital" de nuestros jóvenes. Probablemente, lo que menos estén haciendo los jóvenes con los dispositivos electrónicos sea "leer" en el sentido que hemos dado a ese término en los últimos cinco siglos y debamos empezar a revisar definiciones y conceptos en estas áreas tan sensibles y nucleares del proceso formativo.

\subsection{De la individualidad a la colaboración}

En esta misma línea, pasar de la web 1.0 a la web 2.0, donde la primera nos restringía a las tareas de leer y consumir, mientras que en la segunda se expanden las posibilidades para escribir y producir, permite plasmar una vieja aspiración de la pedagogía activa, la de poner en práctica con pocos recursos los principios de las pedagogías de Decroly, Freinet e incluso Freire, en las que el protagonista es el alumno, que "toma la palabra", y los medios suplen las limitaciones técnicas del docente, cuyo papel adquiere otra dimensión.

Esas transformaciones se apuntan en infinidad de proyectos pedagógicos que hacen de la Red el núcleo de las propuestas formativas: "Las aplicaciones cerradas han dado paso a herramientas abiertas con las que buena parte del profesorado se siente capaz de dar el salto al ciberespacio" (Santos Rego et al. 2012, 137). Se suceden las comunidades de profesorado bloguero, del cual carecemos un censo fiable, aunque en un acertado artículo el profesor Area valora de manera poco favorable la situación a enero de 2011,

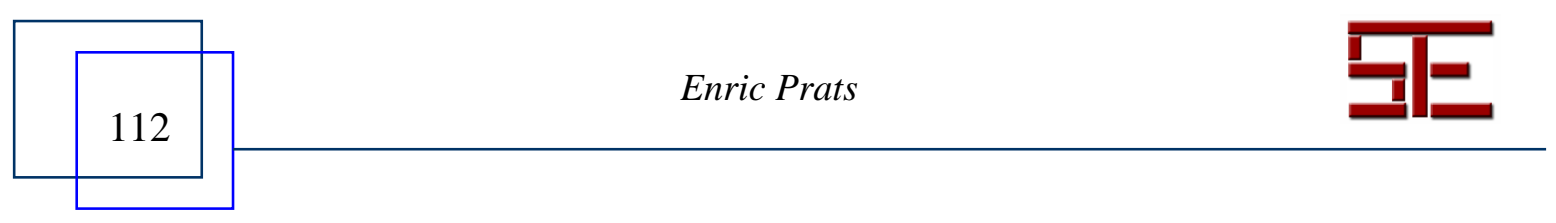




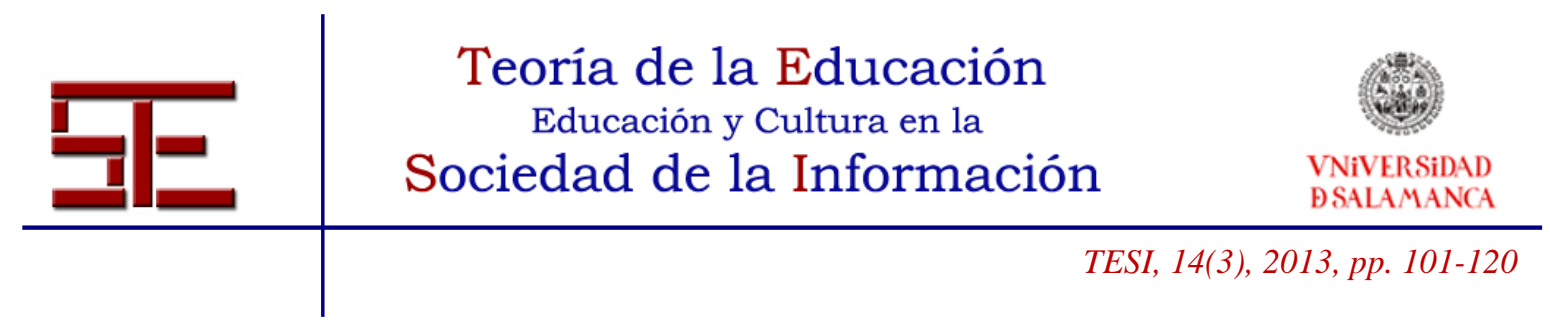

con una supuesta implicación de menos del $1 \%$ de la plantilla docente del magisterio español. También han crecido exponencialmente en los últimos años las comunidades de webquest, una herramienta que permite la creación de propuestas formativas por parte del profesorado; ese crecimiento se ha debido en gran medida al impulso que han dado muchas administraciones educativas con la creación de portales propios para ubicar este tipo de herramientas (Quintana e Higueras 2009). Lo mismo ha sucedido con los proyectos formativos basados en Facebook, cuya experiencia más interesante la encontramos en el Proyecto Facebook, liderado por Alejandro Piscitelli, desde la Cátedra de Procesamiento de Datos, de la Universidad de Buenos Aires, cuya referencia resulta fácilmente localizable en la Red. Finalmente, para cerrar este breve repaso, cabe citar los entornos que permiten la colaboración entre escuelas para integrarse en proyectos participativos en abierto, como el que lidera el Centro de Cultura de Contemporánea de Barcelona, bajo el nombre de Pantalla Global, comisariado por Gilles Lipovetsky y Jean Serroy, basado en el libro homónimo de ambos, donde se invita a centros educativos a producir y subir a la web producciones audiovisuales originales a partir de unos ámbitos de reflexión trabajados en el libro, producciones que serían exhibidas en una fase posterior de exposición ${ }^{1}$.

Todo ello refleja un afán de innovación educativa basado en la conectividad, la colaboración y la generación de conocimiento que, sin ningún género de duda, está suscitando una cierta revitalización de la función del docente en la Red. Sin embargo, cabe anunciar dos alertas acerca de esta frenética actividad educativa y de su base colaborativa.

Por un lado, nos debemos preguntar hasta qué punto ese activismo pedagógico, que se traslada miméticamente a los alumnos, no limita con la dispersión y la superficialidad, en una nueva versión de la pedagogía del zapping, o el browsing, esa facultad humana de ir degustando de manera rápida y ligera, como se hojea un libro sin entrar en el fondo de la cuestión, siguiendo las alarmas de Carr que hemos visto anteriormente. Esta observación remite a la necesidad de abordar los proyectos educativos mediante dispositivos digitales y herramientas colaborativas desde planteamientos pedagógicos bien definidos en términos de valores y finalidades. No se trata de organizar grupos colaborativos o actividades en línea con otras escuelas por el mero hecho de conectarse y usar ordenadores porque los alumnos se lo pasan mejor. Sin duda, el trabajo en equipo, de manera cooperativa, colaborativa o sumativa, debe potenciarse al máximo y puede venir favorecido por las tecnologías al uso, pero eso no es óbice para insistir en la necesidad del trabajo individual, un poco olvidado por el exceso de propuestas de ese tenor.

Además, por otro lado, lo que despiertan las actividades en entornos abiertos es la exigencia de dominar habilidades sociales, además de mínimas habilidades

1

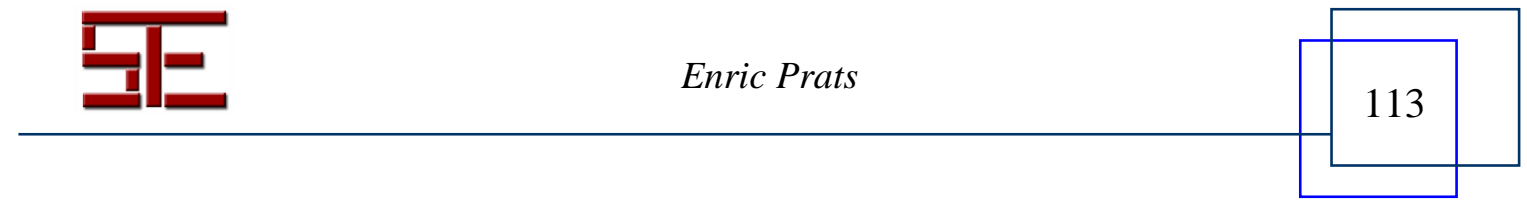




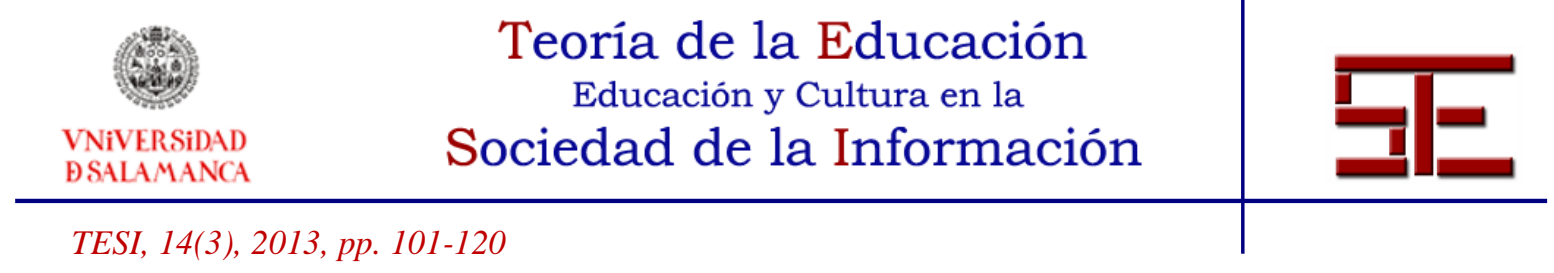

computacionales, que permitan alcanzar los objetivos educativos deseados. Quizás se parte de la premisa optimista de que el hecho de trabajar con ordenadores y en línea motive de por si a los alumnos. Puede ser así en la mayoría de los casos y seguramente en los primeros momentos, pero tanta máquina también termina por aburrir.

De todas formas eso no puede arrinconar una doble reflexión, en primer lugar, acerca de cómo se gestiona la intimidad y la sociabilidad en estos entornos abiertos y, en paralelo a ello, hasta qué punto esa colaboración no esconderá más dosis de impunidad y plagio, un tema que linda con las cuestiones epistemológicas.

\section{4.- TERCER NIVEL: EL RETO PARA LA TEORÍA DE LA EDUCACIÓN}

\subsection{Del dominio experto a la democratización del conocimiento}

Podemos constatar y asumir que las tecnologías digitales han abierto el acceso a la información de una manera impresionante y nunca vista, en línea de lo que los más optimistas califican de democratización del conocimiento, pero también somos conscientes, o deberíamos serlo, de que alcanzar el saber queda bastante lejano y requiere la convergencia de una serie de virtudes que superan el mero dominio de la información.

La taxonomía, como organización del saber a partir del conocimiento compartido que se va forjando a partir de la acumulación y discusión colectiva de las verdades aceptadas por la comunidad, está obligada a convivir con la folksonomía, o procedimiento de organizar el conocimiento a partir de la inteligencia colectiva que se va construyendo a partir de la suma de las porciones que cada uno posee de manera particular. Wikipedia vendría a ser un ejemplo de ello. Construida con las aportaciones de mentes individuales, el proyecto colectivo está alcanzando unos niveles inauditos por la acumulación de contenido pero sobre todo por el volumen de seguimiento que está consiguiendo.

La "paradoja Wikipedia" lanza el reto de asumir la responsabilidad colectiva en la creación de conocimiento. Su uso compulsivo viene de la mano de su rechazo como fuente de autoridad, lo cual nos increpa acerca de la posibilidad real de democratizar el saber. Wikipedia es un producto típicamente 2.0, fruto de un trabajo altruista, horizontal y democrático (en el doble sentido de universal e igualitario), entre otras características, que pone en conexión el conocimiento compartido por sus editores, con el objetivo de favorecer el desarrollo de la inteligencia colectiva, entendida como la "perspectiva espiritual, finalidad última de la cibercultura" (Lévy 1997). La diferencia entre el conocimiento compartido y la inteligencia colectiva radica en que ésta exige establecer mecanismos de conocimiento en abierto, traducido en las licencias copyleft (Creative Commons) que son fruto de la ética hacker (software libre), dos características intrínsecas a la misma Red (Ortega y Rodríguez 2011, 54).

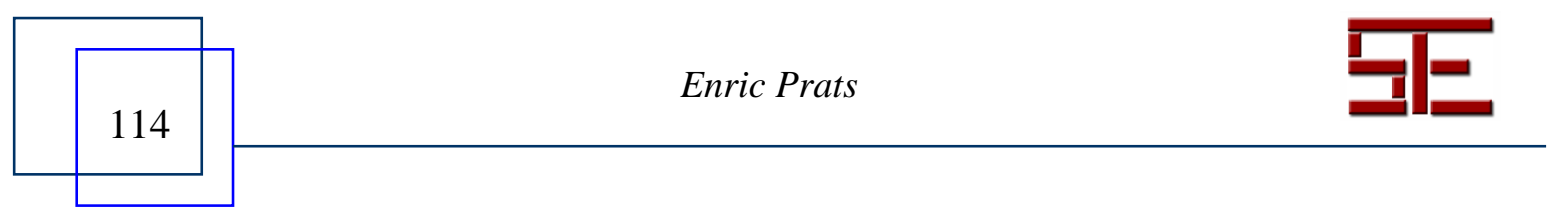




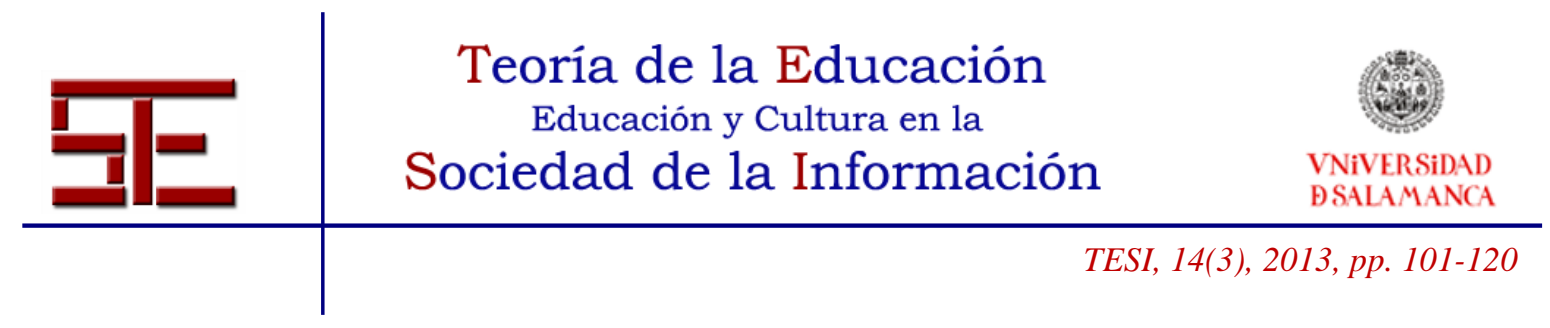

Lo que subyace en el trasfondo del wikipediano medio es la convicción de que "el conocimiento debe ponerse a disposición de quien lo necesite, libremente, como resultado del esfuerzo compartido y desinteresado de una comunidad atópica que afirma su radical independencia en la disponibilidad y alterabilidad de los contenidos que distribuyen gratuitamente" (Ortega y Rodríguez 2011, 61). Ese mismo principio es el que inspira al espíritu científico. Por ejemplo, Mendeley es una herramienta que ofrece un espacio para que académicos e investigadores intercambien reflexiones, resultados de investigaciones y otro material en bruto, lo cual genera valor a la circulación del conocimiento libre, que dicho sea de paso empieza a poner en entredicho la viabilidad y el futuro del modelo que conocemos hoy de difusión científica ${ }^{2}$.

La relativización de que la web 2.0 permite universalizar y democratizar el conocimiento se acompaña de las dudas que se ciernen nuevamente sobre estos mecanismos acerca de cómo debemos entender, en este contexto, el concepto de autoridad. En realidad, el conocimiento en abierto abre los nodos en la creación y diseminación del saber, en una nueva versión de los postulados desescolarizantes de Illich i Reimer, cuyas aportaciones literarias son suficientemente conocidas. Por ejemplo, como expertos de la educación, ¿estamos preparados para aprender a perder la autoridad sobre el saber pedagógico?

\subsection{La Teoría de la Educación, a remolque}

La pregunta que cierra el epígrafe anterior ayuda a cerrar las reflexiones de este artículo, acerca del papel de la teoría de la educación en un contexto de conocimiento compartido en abierto. La aparición de tecnologías nuevas ponen continuamente en suspenso y en transición a nuestras actitudes y hábitos de trabajo, e incluso de vida, por lo que no debería sorprendernos las polémicas acerca de sus ventajas y peligros. Lo que no pasa desapercibido a cualquier observador es que las tecnologías 2.0 sitúan en un enfoque más amplio distintas tendencias que se vienen produciendo desde hace algunas décadas en nuestras sociedades: postmodernidad, globalización, liquidez, capitalismo de tercera generación. Todo lo cual nos obliga, sin perder más tiempo, a plantearnos principios y estrategias algo caducas.

Como no podría ser de otra manera, el debate acerca del origen de la expresión "web 2.0 " no es gratuito y, como toda polémica nominal, mantiene en vilo a la comunidad de internautas y usuarios de la red. Se suele atribuir a Tim O'Reilly la paternidad del asunto, a partir de una sesión de trabajo en 2003, como expresa en "What Is Web 2.0"3. Sin embargo, todo parece indicar que deberíamos hablar, al menos en este caso, de maternidad, ya que fue Darcy DiNucci, consultora informática, quien en un artículo de 1999 afirmaba el cambio que se estaba avecinando en la World Wide Web: "Fragmented Future"4.

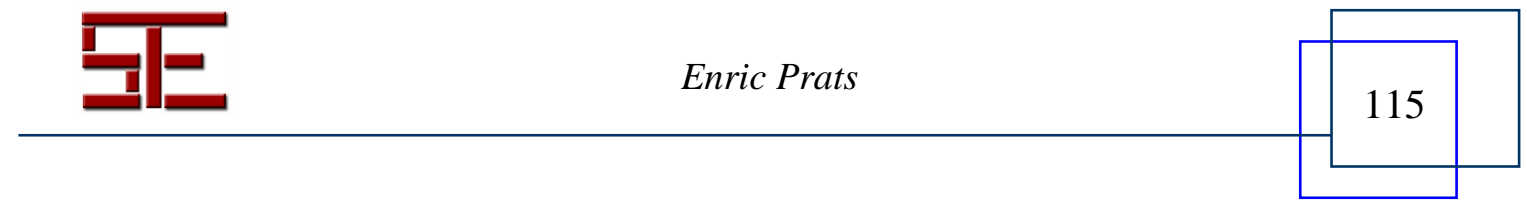




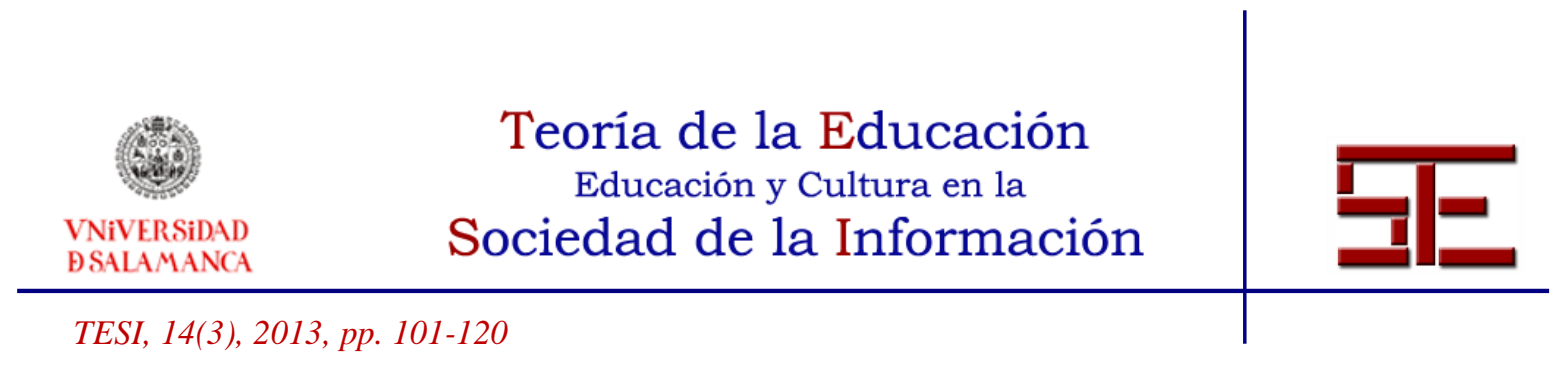

Los análisis más agudos sobre la Red y los dispositivos a qué da lugar refieren un proceso de convergencia que, junto con los medios clásicos de comunicación, dibujan un panorama nuevo con los medios sociales. Henry Jenkins recoge que el profeta de esa convergencia de medios fue un politólogo del Massachusets Institute of Technology, Sola Pool, quien en 1983 ya lanzaba esa idea, alejada de la impresión común que suponía la dispersión existente con la radio, la televisión, el cine y la publicidad estática, aumentada con la aparición del ordenador. Si bien la tecnología se ha instalado en todos los hogares con una variedad ingente de dispositivos, desde mandos a distancia a teléfonos inalámbricos o terminales móviles, la centralización o concentración parece inevitable: "La digitalización estableció las condiciones para la convergencia; los conglomerados corporativos la convirtieron en un imperativo" (Jenkins 2008, 22). En un terreno analógico impera la dispersión; en uno digital domina la concentración.

Esta línea de análisis, quizás más realista, cabría contrastarla con el pronóstico lanzado a mediados de la década de 1990 por Nicholas Negroponte, influyente gurú de las tecnologías y promotor de iniciativas célebres, como el proyecto "One Laptop for Child" para abastecer de dispositivos móviles a población empobrecida, y que ha dado pie a numerosas iniciativas del mismo estilo. Sus augurios vaticinaban la sustitución de la televisión, la radio y la prensa escrita por Internet y los nuevos medios digitales, un augurio que no se ha producido en esa dirección precisamente, sino que ha significado un reposicionamiento de aquellos "viejos medios pasivos", según la terminología de Negroponte, con la orientación marcada por los "nuevos medios activos". Lo que nos ilustran estos vaticinios es precisamente el cambio que estaban induciendo las tecnologías hacia todo lo que fuera en abierto y que significara la adopción de un rol activo por parte de usuarios, hasta entonces sumidos en la pasividad de grises dispositivos, como se les ha venido caricaturizando.

En suma, a catorce años de su acuñación, nos debatimos todavía acerca de las bondades e imperfecciones de estas herramientas, cuando el mundo de la educación, con más o menos éxito, las está implantando en su quehacer diario. En realidad, la teoría de la educación reflexiona sobre lo conocido, a veces sobre lo archiconocido, pero muestra una cierta incapacidad a pensar en clave prospectiva, a ofrecer escenarios desde el análisis de tendencias. Ahora que nos hemos acostumbrado a la web 2.0, hay que empezar a pensar en la web 3.0, la web semántica, llamada también inteligente, y de qué manera impactará en nuestros marcos teóricos. Fuera de nuestro campo, se está ya hablando de educación y pedagogía 3.0, de educación expandida y de aprendizaje invisible, en un intento de resituar los términos y las categorías en un terreno más cercano a la realidad educativa. ¿Tenemos algo que decir a todo ello desde la teoría de la educación?

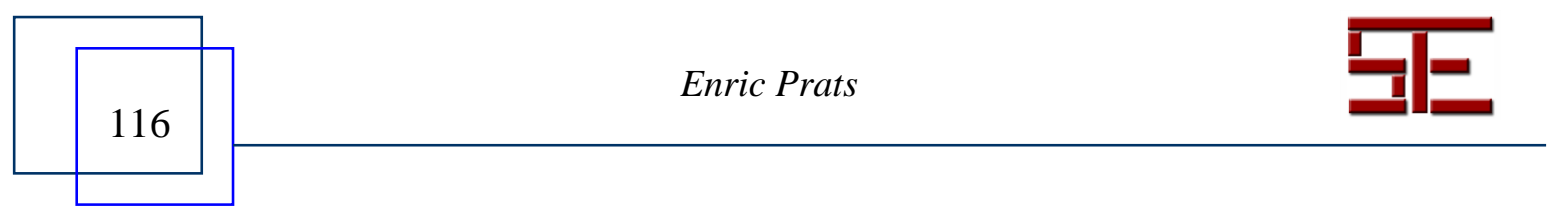




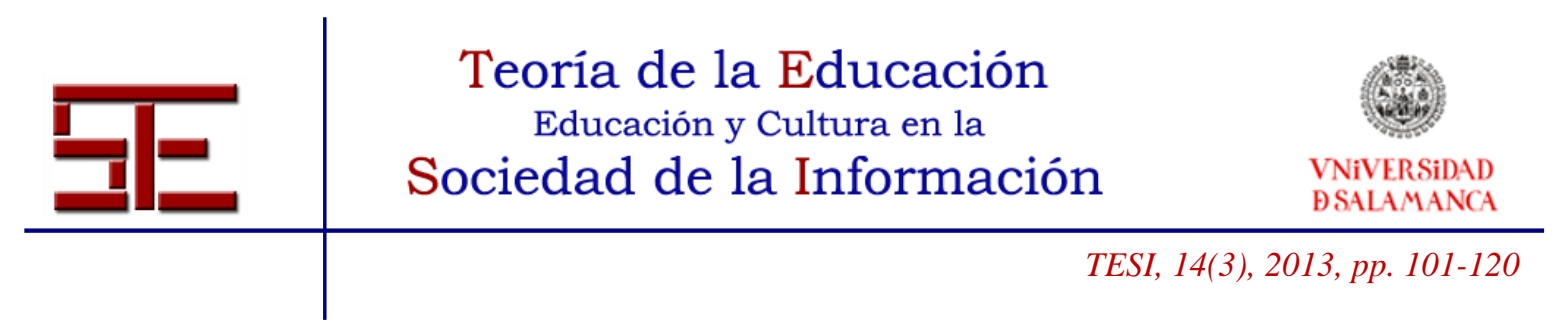

\section{5.-DISCUSIÓN}

En una cultura de 140 caracteres quizás debamos preguntarnos cual es el lugar reservado a la educación, entendida como un proceso lento, dilatado y sin límites. Si el medio es el mensaje, como ya anunció McLuhan en los sesenta, nos debería preocupar el sentido y contenido de ese mensaje en unos medios sociales convergentes en tecnología pero sobre todo en discurso. La reducción del mensaje incrementa las posibilidades de alcanzar más audiencia, que a su vez se convierte en emisora de nuevos mensajes, de la misa manera que el empaquetamiento en unidades pequeñas de información aumenta las posibilidades de llegar más lejos, por un simple principio economicista. Por supuesto que la pérdida de cantidad incidirá en el volumen de conocimiento alcanzable, pero también nos hará reflexionar sobre la necesidad de que esa reducción se aproveche para aumentar la calidad de ese conocimiento. Lo catastrófico, desde el punto de vista pedagógico, sería justamente lo contrario: el aumento de ruido podría ser letal y la tarea de educar deberá ser precisamente la de tamizar ese ruido.

Toda interacción genera incertidumbre, más cuando los interactuantes carecen de contacto físico o presencial, cara a cara, tangible y no virtual. Las tecnologías han multiplicado las oportunidades para esa interacción de la misma manera que han reducido los riesgos de una comunicación ineficaz desde el punto de vista técnico. Lo que la educación formal deberá indagar es en la localización de dispositivos instructivos que permitan convertir esa interacción en diálogo, en construcción conjunta de nuevo conocimiento, como advierte la etimología del término. El diálogo es quizás de las pocas herramientas que permiten reducir la incertidumbre y aumentar la confianza en el otro, más en un contexto no presencial. Ahí tenemos otro reto educativo.

Por supuesto, todo ello requiere de una actitud corporativa bien distinta por parte del profesorado. A las dificultades técnicas que pueda suponer la integración de tecnologías poco conocidas, habrá que añadir las complicaciones derivadas de una errónea interpretación de lo que las tecnologías permiten. La apertura y versatilidad de los nuevos medios asustan también al más seguro de los docentes, en la medida que esas dos virtudes de los medios 2.0 incrementan de manera exponencial la incertidumbre sobre el proceso educativo y, por supuesto, en sus resultados.

Una vez iniciado el proceso de transición hacia una escuela digital quizás no haya retorno posible. Lo incierto del resultado no quita validez al hecho de que el reclamo de la digitalización debe suponer un compromiso colectivo, concertado entre equipos docentes y familias, para acometer conjuntamente esos retos. No es sencillo trabajar con wikis, blogs, nubes, Facebook o Twitter, sin perder el control de la situación. Quizás el docente deberá acostumbrarse exactamente a saber perder ese control. Pero lo que nadie le va a quitar es la capacidad para establecer objetivos claros y precisos y para marcar el camino. Después, cada cual a lo suyo. Esa es la máxima de lo digital.

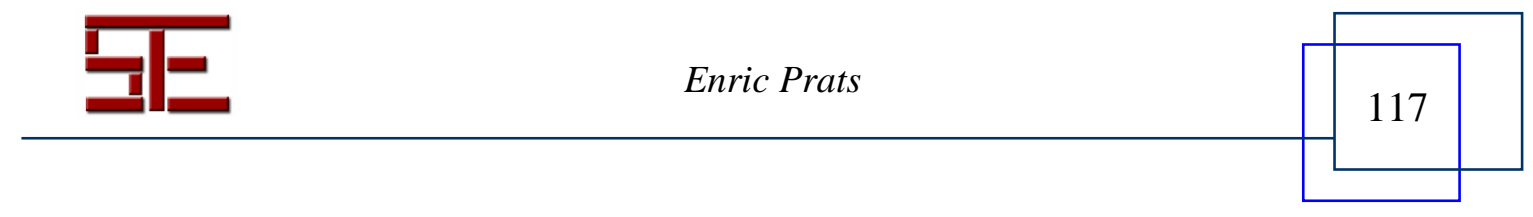




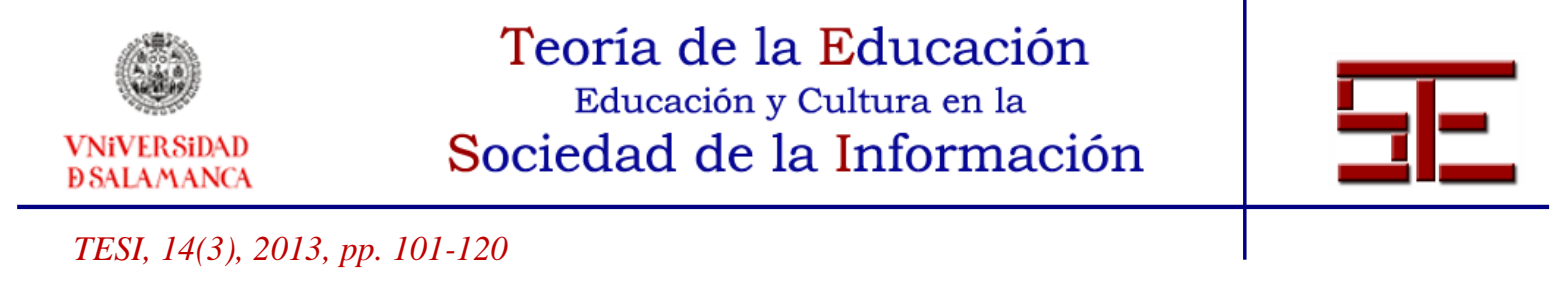

Por lo demás, como alerta Livingstone, falta mucho recorrido para llegar a demostrar los beneficios pedagógicos que aportan las tecnologías, ante lo cual nos insta a plantear una revisión ideológica profunda sobre la manera cómo hemos integrado ordenadores en las aulas, pensando realmente si el débil impacto educativo y social ha compensado el abundante margen comercial ganado por las empresas proveedoras y los réditos electorales de los políticos de turno (Livingstone 2011, 22). Esa ambición de jugar a ser dioses se da de bruces con la realidad, cruzada por intereses que vistos desde la humildad se nos escapan en cada esquina.

\section{REFERENCIAS}

Apple, M. W. y Beane, J. A. (1997). Escuelas democráticas. Madrid: Morata.

Area, M. (2011) ¿Cuántos profesores 2.0 hay en las redes sociales en España? ¿Son muchos o pocos? Ordenadores en el aula. Blog de Manuel Area. Extraído el 31 mayo, 2013, de http://ordenadoresenelaula.blogspot.com.es/2011/01/cuantosprofesores-20-hay-en-nuestro.html

Bennett, S.; Maton, K.; Kervin, L. (2008) The 'digital natives' debate: A critical review of the evidence. British Journal of Educational Technology, 39 (5), 775-786.

Da Silva, L. (2003) Intervención del Excelentísimo Señor Presidente de la República Federativa del Brasil Luiz Inácio Lula da Silva. Nueva York, Naciones Unidas. Debate General del $58^{\circ}$ Periodo Ordinario de Sesiones de la Asamblea General de las Naciones Unidas. Extraído el 18 mayo, 2013, de http://www.un.org/webcast/ga/58/statements/brazil-spanish.htm

Carr, N. (2010) Superficiales ¿Qué está haciendo internet con nuestras mentes? Madrid, Taurus.

Castillo Gómez, A.; Sáez, C. (1994) Paleografía versus alfabetización. Reflexiones sobre historia social de la escritura. Signo. Revista de historia de la cultura escrita, 1, 133-168.

DOC (2012) "Conclusiones del Consejo, de 26 de noviembre de 2012, sobre alfabetizaciones múltiples" Diario Oficial de la Unión Europea 393 de 19.12.2012. Extraído el 31 mayo, 2013, de http://eurlex.europa.eu/LexUriServ/LexUriServ.do?uri=OJ:C:2012:393:0001:0004:ES:PD $\mathrm{F}$

Jenkins, H. (2008) Convergence Culture. La cultura de los convergencia en los medios de comunicación. Barcelona: Paidós (original de 2006, New York University).

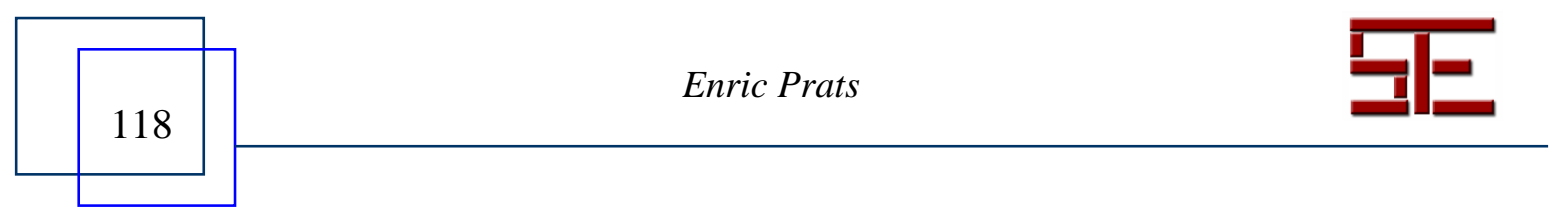




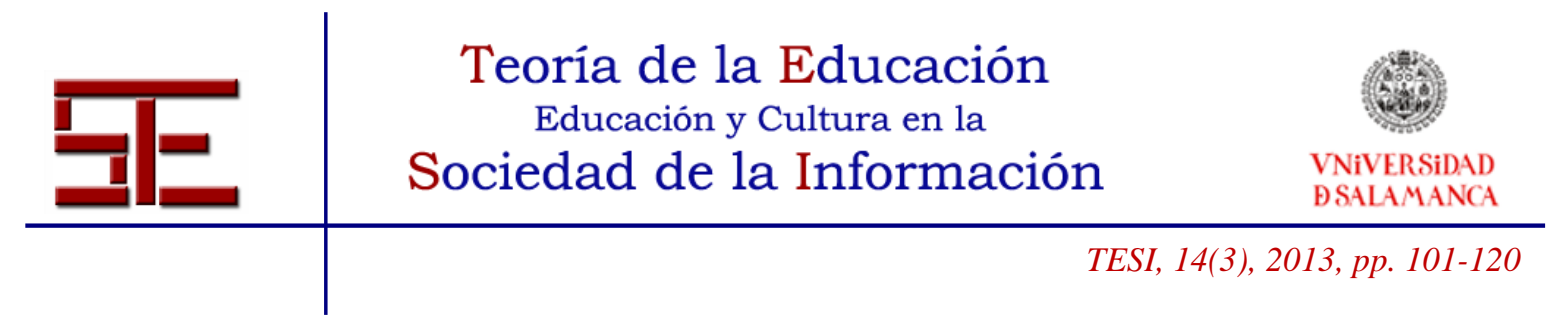

Laudo, X.; Prats, E. (2013) El lugar de la autonomía en la pedagogía y la educación postmodernas. Teoría de la Educación en la Sociedad de la Información, 14 (1), 48-262. Extraído el 31 mayo, 2013, de http://hdl.handle.net/10366/121856

Lévy, P. (1997) Essai sur la cyberculture: l'universel sans totalité. Extraído el 31 mayo, 2013, de http://bit.ly/xlhgmM

Livingston, S. (2011) Critical reflections on the benefits of ICT in education. Oxford Review of Education, 38 (1), 9-24.

Negroponte, N. (1995) Being digital. Nueva York: Alfred A. Knopf.

Ortega, F.; Rodríguez, J. (2011) El Potlatch digital. Wikipedia y el triunfo del procomún y el conocimiento compartido. Madrid: Cátedra.

Pedró, F. (2011) Tecnología y Escuela: lo que funciona y por qué. Documento básico. Madrid: Fundación Santillana (XXVI Semana Monográfica de la Educación: La Educación en la Sociedad Digital).

Prensky, M. (2001) Digital Natives, Digital Immigrants. Part 1. On the Horizon (9) 5, 16. Extraído el 31 mayo, 2013, de http://www.marcprensky.com/writing/Prensky\%20-

\%20Digital\%20Natives,\%20Digital\%20Immigrants\%20-\%20Part1.pdf

Quintana, J.; Higueras, E. (2009) Las webquest, una metodología de aprendizaje cooperativa, basada en el acceso, el manejo y el uso de información de la red. Barcelona: Octaedro-ICE de la Universidad de Barcelona. Extraído el 31 mayo, 2013, de http://www.octaedro.com/ice/pdf/11CUADERNO.pdf

Santos Rego, M.A.; Etxeberria Balerdi, F.; Lorenzo Moledo, M.; Prats, E. (2012) Web 2.0 y redes sociales. Implicaciones educativas. En García Aretio, Lorenzo Sociedad del conocimiento y educación (pp. 124-148). Madrid: Uned.

Viñao, A. (1992) Alfabetización y alfabetizaciones. En Agustín Escolano (dir.) Leer y escribir en España. Doscientos años de alfabetización (pp. 385-410). MadridSalamanca: Fundación Germán Sánchez Ruipérez.

\section{NOTAS}

${ }^{1}$ El proyecto está disponible en su portal web, en http://pantallaglobal.cccb.org/es/ (consultada el 31 mayo, 2013).

${ }^{2}$ Puede consultarse la página web del producto en http://www.mendeley.com (consultada el 31 mayo, 2013)

${ }^{3}$ Consúltese en http://oreilly.com/web2/archive/what-is-web-20.html (consultada el 31 mayo, 2013).

${ }^{4}$ Disponible http://darcyd.com/fragmented_future.pdf (consultada el 31 mayo, 2013).

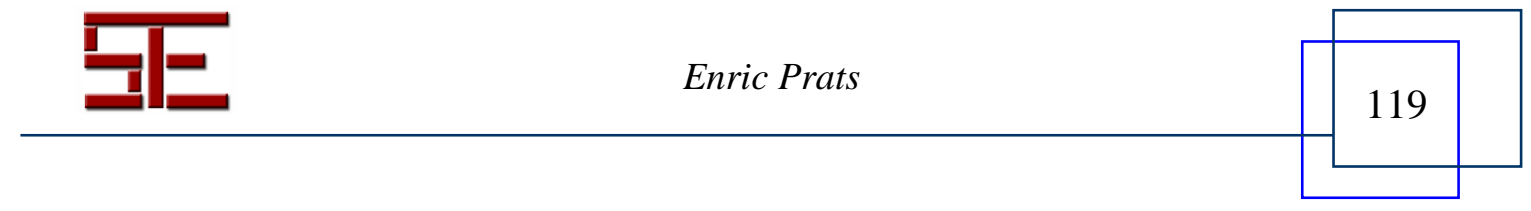




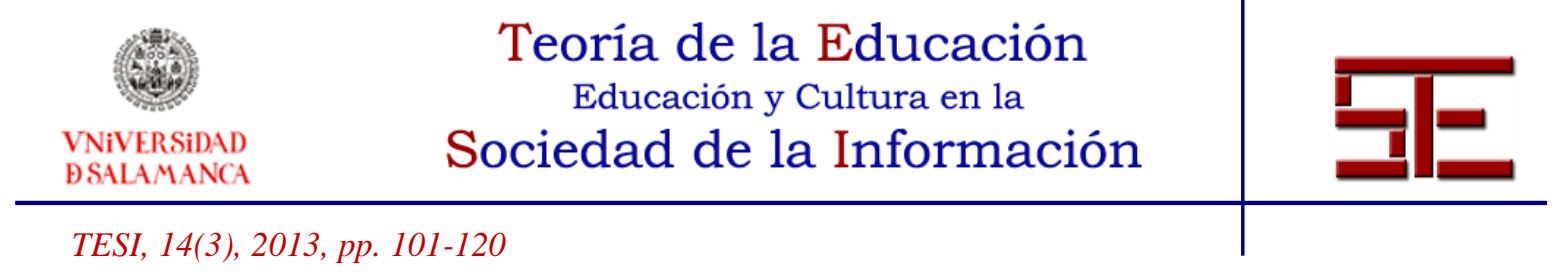

Para citar el presente artículo puede utilizar la siguiente referencia:

Prats, E. (2013). Jugando a ser dioses: puntos críticos de las tecnologías en educación. Revista Teoría de la Educación: Educación y Cultura en la Sociedad de la Información. 14(3), 101-119 [Fecha de consulta: dd/mm/aaaa].

http://campus.usal.es/ revistas_trabajo/index.php/revistatesi/article/view/11353/11770

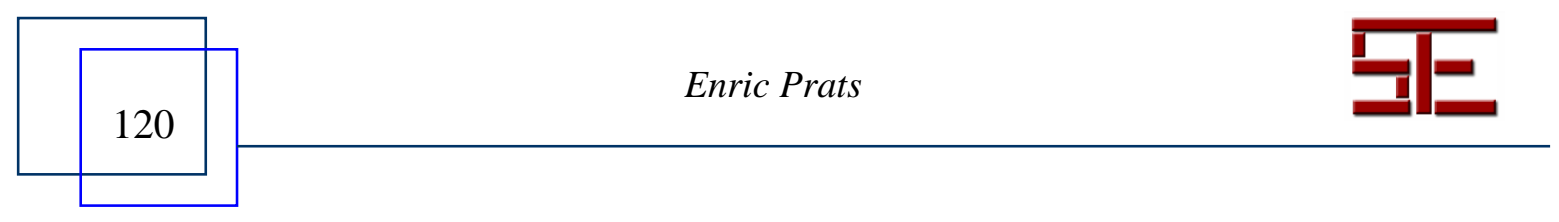

